\title{
Новые данные по питанию доминантных видов рыб в горных озерах Большой и Малый Вудъявр (Хибины, Мурманская область)
}

\author{
Зубова Е.М, Кашулин Н.А., Терентьев П.М. \\ Институт проблем промылиленной экологии Севера КНЦ РАН, Anamumbl, zubova@inep.ksc.ru
}

\begin{abstract}
Аннотация. Исследовано питание доминантных видов рыб горных озер Большой и Малый Вудъявр - арктического гольца Salvelinus alpinus и корюшки Osmerus eperlanus. Было выявлено, что особенности питания гольцов из Б. и М. Вудъявра схожи: характерен смешанный тип питания (ракообразный зоопланктон и хирономиды) с элементами хищничества девятииглой колюшкой Pungitius pungitius. Количественные показатели содержимого их желудков значимо не различались. Особенности питания корюшки в Б. Вудъявре близки к таковым гольца этого озера: имеет смешанный тип питания (ракообразный зоопланктон и хирономиды) с преобладанием зоопланктонных организмов.

Ключевые слова: оз. Большой Вудъявр, оз. Малый Вудъявр, доминантный вид, питание, арктический голец Salvelinus alpinus, корюшка Osmerus eperlanus.
\end{abstract}

\section{New data on the food of dominant fish species from the Bolshoy and Malyy Vudyavr mountain lakes (Khibiny, Murmansk region)}

\author{
Zubova E.M., Kashulin N.A., Terentyev P.M. \\ Institute of the North Industrial EcologyProblems KSC RAS, Apatity, zubova@inep.ksc.ru
}

\begin{abstract}
The feeding of of dominant fish species from the Bolshoy and Malyy Vudyavr mountain lakes - the Arctic char Salvelinus alpinus and smelt Osmerus eperlanus was studied. It was found that the feeding characteristics of the char from Bolshoy and Malyy Vudyavr are similar: a mixed type of feeding (crustacean zooplankton and chironomids) with elements of predation by a nine-needle stickleback Pungitius pungitius. Quantitative indicators of the contents of their stomachs did not significantly differ. The feeding peculiarities of smelt from Bolshoy Vudyavr are close to those of the char of this lake: it has a mixed type of nutrition (crustacean zooplankton and chironomids) with a predominance of zooplankton organisms.
\end{abstract}

Key words: Bolshoy Wudyavr Lake, Malyy Wudyavr Lake, dominant species, feeding, char Salvelinus alpinus, smelt Osmerus eperlanus.

\section{введение}

Озера Большой и Малый Вудъявр находятся в южной части Хибинского массива и входят в озерно-речную систему р. Большая Белая (водосбор р. Нива, бассейн Белого моря). Они относятся к классу малых озер $\left(<10\right.$ км $\left.^{2}\right)$ (Михайлов и др., 2007). Свыше 90 лет оз. Б. Вудъявр служит приемником шахтных, производственных (ОАО «Апатит») и коммунальных (г. Кировск) сточных вод. Загрязнение озера привело к повышению в воде общей минерализации, концентрации тяжелых металлов и алюминия, а также биогенных элементов, способствующих интенсивному развитию здесь фито- и зоопланктона. Оз. М. Вудъявр не испытывает прямого загрязнения. Его воды по химическому составу соответствуют природному фону и относятся к ультраолиготрофному статусу вод (Кашулин и др., 2008, 2013). В 40-х гг. прошлого века в составе ихтиофауны оз. Б. Вудъявр насчитывалось 5 видов рыб: кумжа Salmo trutta, арктический голец Salvelinus alpinus, обыкновенный сиг Coregonus lavaretus, европейский хариус Thymallus thymallus и налим Lota lota (Материалы..., 1940). Отмечается практически полное исчезновение рыб в период сброса флотационных отходов АНОФ-І в водоем. После закрытия фабрики, в 2006-2008 гг. в уловах встречались лишь арктический голец и девятииглая колюшка Pungitius pungitius. В настоящее время в озере также встречаются кумжа и инвази́вный вид европейская корюшка Osmerus eperlanus, численность которой растет (Терентьев и др., 2017). В уловах оз. М. Вудъявр встречались лишь голец и налим (табл. 1). Доля корюшки в уловах из Б. Вудъявра выше, чем у гольца и составляет 61 \% (табл. 1). В оз. М. Вудъявр доминирует голец, 
который, несмотря на обитание в условно-чистых водах, имеет значимо меньшие линейно-весовые характеристики, нежели в Б. Вудъявре (Терентьев, 2010).

Целью настоящей работы был сравнительный анализ питания доминирующих видов рыб оз. Б. и М. Вудъявр, различающихся условиями обитания, составом и струкурой ихтиофауны.

Таблица 1. Процентный состав видов рыб в уловах из озер Большой и Малый Вудъявр, 2004-2019 гг. Table 1. The percentage of fish species in catches from Lakes Bolshoy and Malyy Vudyavr, 2004-2019

\begin{tabular}{|l|c|c|}
\hline Виды рыб & Большой Вудъявр & Малый Вудъявр \\
\hline Голец & 38.3 & 99.5 \\
\hline Кумжа & 1.2 & - \\
\hline Корюшка & 60.5 & - \\
\hline Налим & - & 0.5 \\
\hline
\end{tabular}

Примечание. Доминантные виды составляют $\geq 20 \%$ от улова, субдоминантные - 8-20 \% - по: Решетников, Богданов, 2011. Здесь и в табл. 2-4 «-»- отсутствие в выборке.

\section{материал и методы}

Для качественного и количественного анализа питания гольца и корюшки в озерах Б. и М. Вудъявр в осенний период (сентябрь, октябрь) 2004-2019 гг. было просмотрено содержание желудков 57 особей (табл. 2-4), согласно известным руководствам (Руководство..., 1961; Методическое..., 1974). Для оценки питания исследуемых видов рыб были выделены следующие размерные группировки: для гольца из оз. Б. Вудъявр - 100-199, 200-299, 300-399 мм, для корюшки из оз. Б. Вудъявр - 90-120 и 121-150 мм и для гольца из оз. М. Вудъявр - 90-150, 151-200 и 201-250 мм.

\section{Результаты}

Гольцы в исследуемых озерах были представлены особями со средним числом тычинок на первой жаберной дуге, равным 23 (19-26). Средние линейно-весовые характеристики гольца из Б. Вудъявра (232 \pm 1.9 (122-410) мм и $213 \pm 125.7$ (17-1140) г) были значимо больше $(p<0.001)$, нежели у гольца из М. Вудъявра (158 $\pm 2.3(92-263)$ мм и $56 \pm 4.6(5-293)$ г). Корюшка из Б. Вудъявра имела среднюю длину и массу соответственно $122 \pm 1.9$ (93-174) мм и $17 \pm 1.1(5-91)$ г.

Анализ спектра питания гольца из оз. Б. Вудъявр показал, что он включает относительно небольшой набор пищевых объектов, относящихся к 8 родам и к 3 семействам беспозвоночных животных, а также рыбу (табл. 2). Питание гольца из оз. М. Вудъявр включало большее число объектов питания: 14 родов и 3 семейства беспозвоночных животных, рыбу. Гольцы из оз. Б. Вудъявр в целом по выборке (длина 100-399 мм) в основном питаются бентосными организмами. Они встречались у $87 \%$ особей гольца и составили 75 \% по массе от пищевого комка. Бо́льшая доля по массе принадлежала личинкам хирономид. Рыба (девятииглая колюшка) и зоопланктонные организмы (в основном ветвистоусые ракообразные) составили 15 и $10 \%$ от массы содержимого желудка соответственно. В пищевом комке гольцов из оз. М. Вудъявр (длина 90-250 мм) зооплактонные (ветвистоусые ракообразные), бентосные (в основном личинки хирономид) организмы и рыба (девятииглая колюшка) имеют в среднем близкие доли по массе (табл. 2). При этом наиболее часто в желудках встречался зоопланктон. Гольцы из оз. Б. Вудъявр длиной до 200 мм в основном питаются ветвистоусыми ракообразными и остракодами (табл. 2). С увеличением линейных характеристик рыб до 300 мм, доля по частоте встречаемости и по массе у зоопланктона не снижаются, но по массе значительную долю в пищевом комке (до 29 \%) начинают занимать личинки хирономид, появляется рыба. Начиная с 300 мм, в составе пищевого комка резко снижается доля зоопланктонных организмов, и растет доля хирономид (до 87 \% - по встречаемости и до $81 \%$ - по массе от пищевого комка), содержание рыбы в пищевом комке почти не меняется. Гольцы из оз. М. Вудъявр длиной до 150 мм в основном питаются ракообразным зоо- 


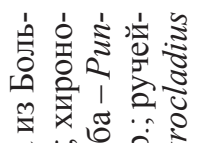

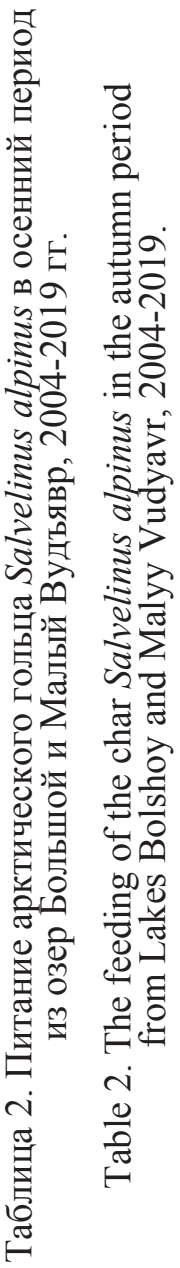

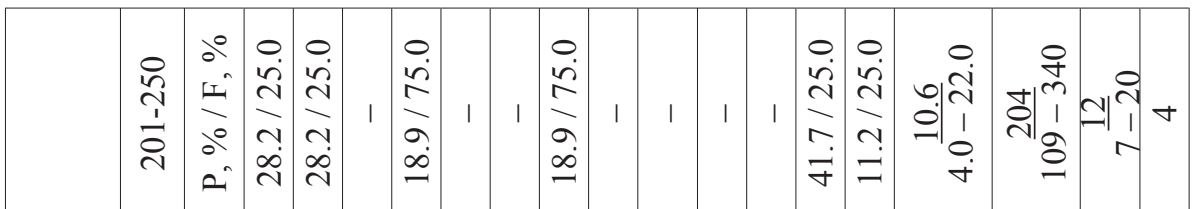

要

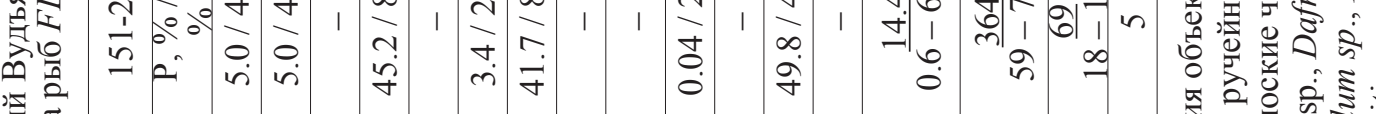

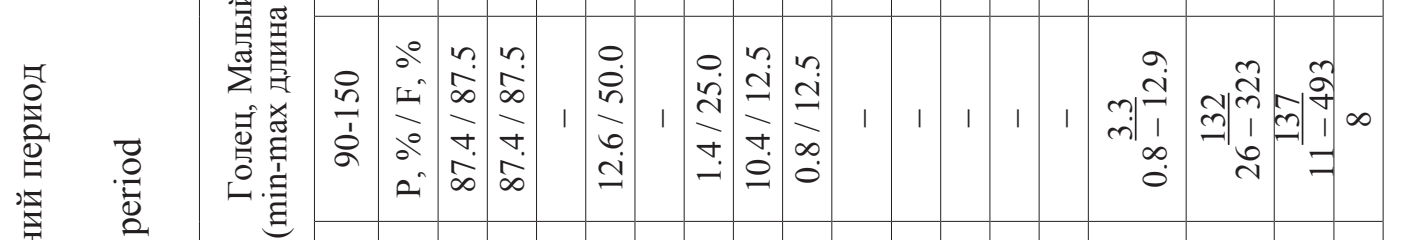

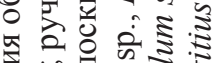
के के

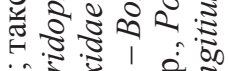

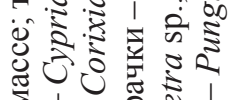

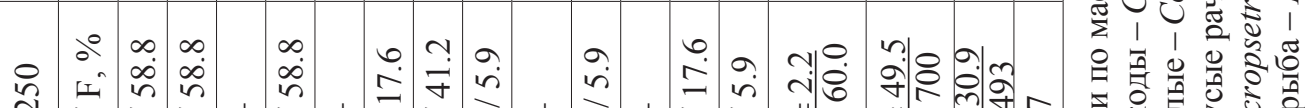

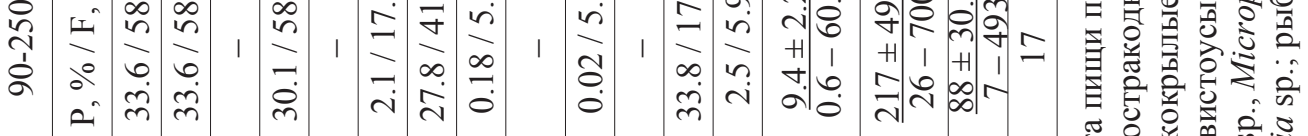

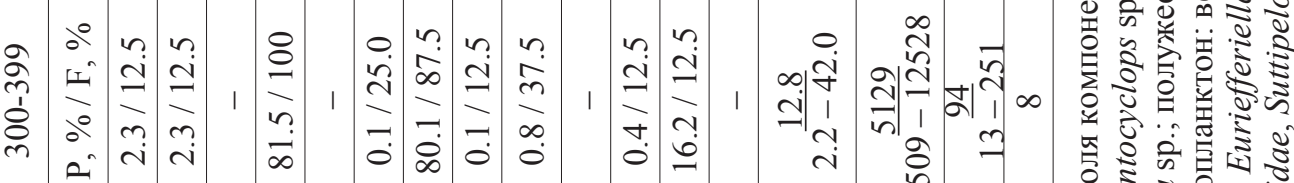

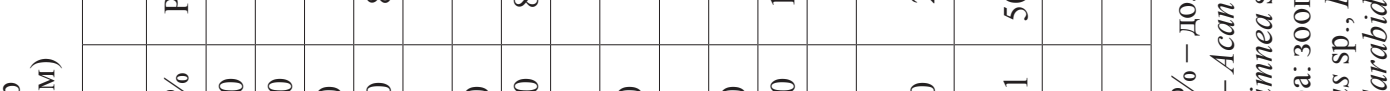

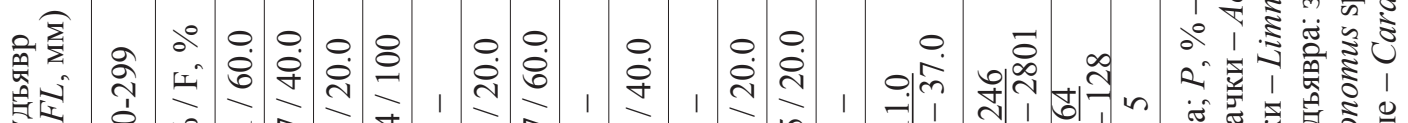

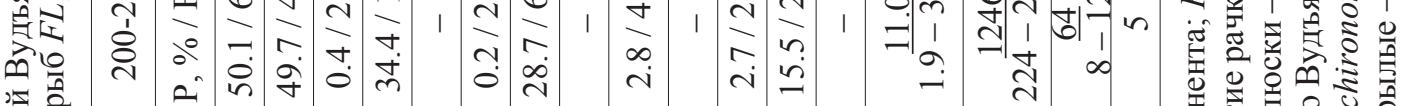

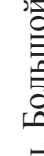
章

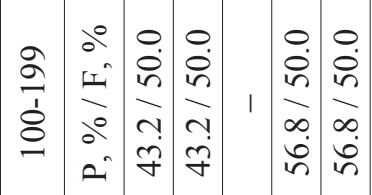

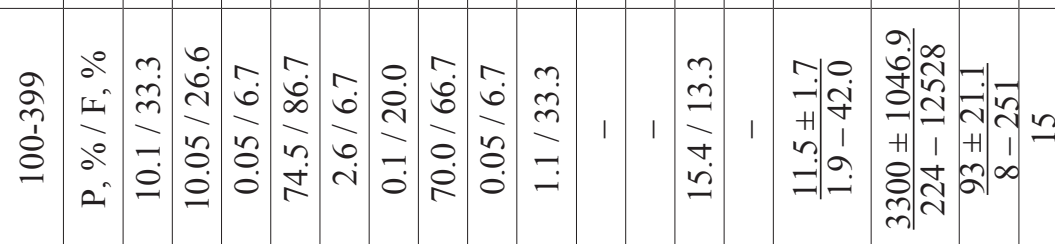

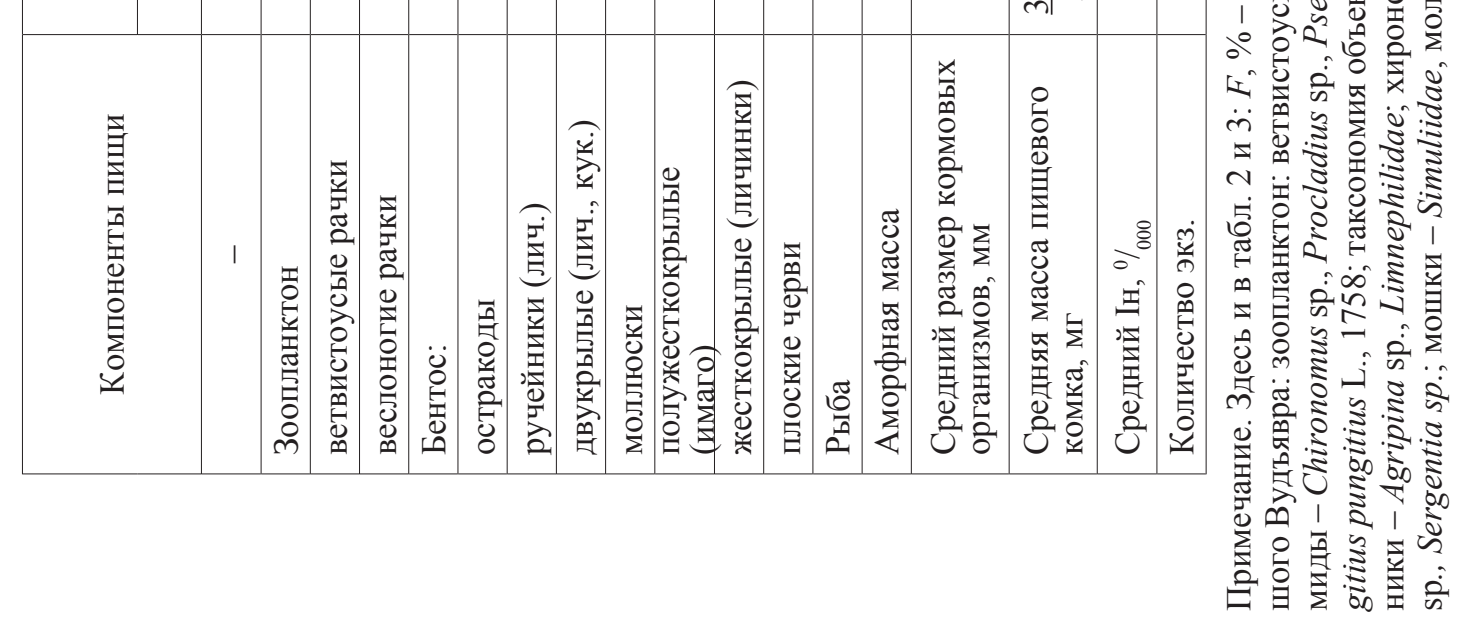

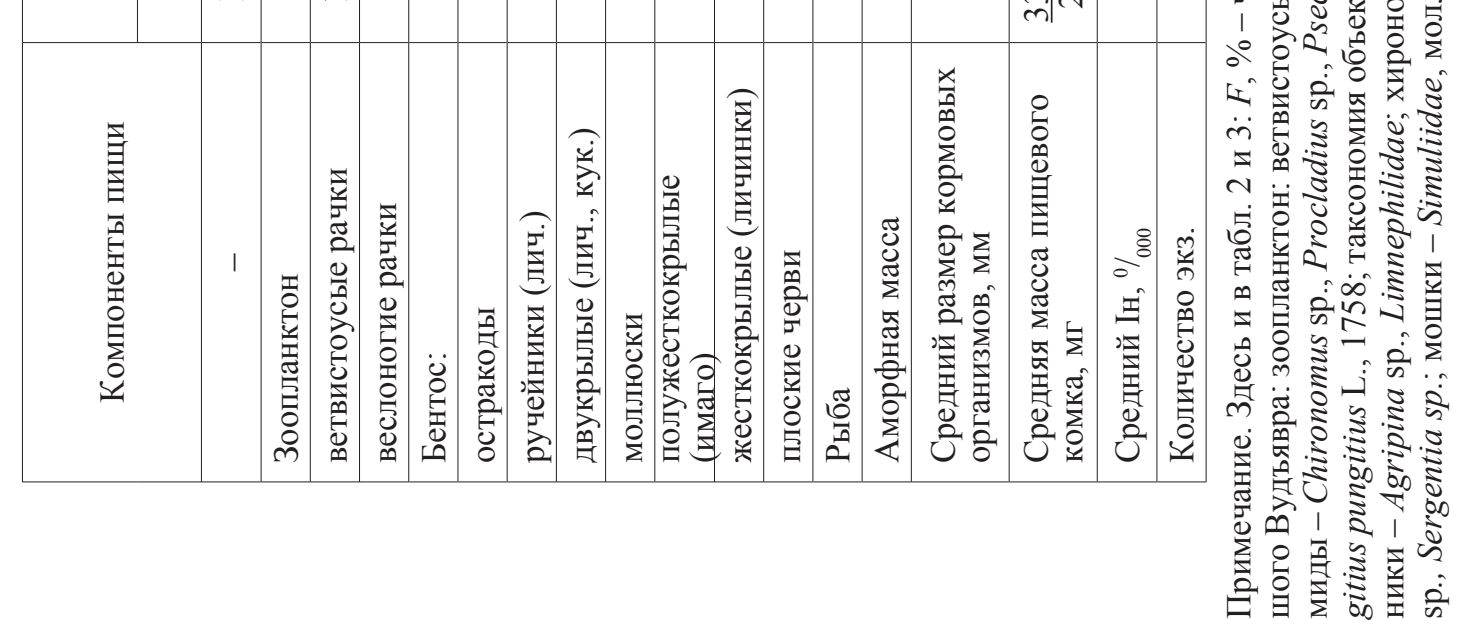


планктоном (до 88 \% по частоте встречаемости и по массе) (табл. 2), незначительную долю составляют личинки хирономид. С увеличением линейных характеристик (151-250 мм) в желудках появляется рыба, которая занимает от 42 до 50 \% от доли пищевого комка.

Несмотря на то, что у гольцов размера 151-250 мм частота встречаемости зоопланктонных организмов и хирономид довольно высока (от 25 до 80 \%), их доля по массе от пищевого комка немного ниже, чем у рыбы. Средний размер объектов питания гольцов из озер Б. и М. Вудъявр в целом для выборок значимо не различается (табл. 2), с увеличением размерных характеристик гольцов размеры объектов питания растут. Абсолютные размеры пищевого комка гольцов в целом для выборки имеют значимо большие показатели $(p>0.01)$ для рыб из оз. Б. Вудъявр, относительные (Iн) - не различаются (табл. 2).

Корюшка в оз. Б. Вудъявр питается, как зоопланктонными организмами (в основном ветвистоусые ракообразные), так и бентосными (хирономиды): в целом для выборки (длина 90-150 мм) встречаются у 90 и 40 \% особей соответственно (табл. 3). Причем основную долю по массе от пищевого комка составляют ветвистоусы ракообразные - до 89 \%. Особенности питания с увеличением линейных характеристик корюшки особо не меняются (табл. 3). Размеры объектов питания корюшки в оз. Б. Вудъявр с увеличением линейных характеристик рыб растут (табл. 3) и в целом для выборки имеют значимо меньшие характеристики ( $>$ > 0.05), нежели для гольцов из озер Б. и М. Вудъявр (табл. 2, 3). То же самое наблюдается и при сравнивании абсолютных и относительных показателей размера пищевого комка (табл. 3).

Таблица 3. Питание европейской корюшки Osmerus eperlanus в осенний период из озера Большой Вудъявр, 2004-2019 гг.

Table 3. The feeding of the smelt Osmerus eperlanus in the autumn period from Lake Bolshoy Vudyavr, 2004-2019.

\begin{tabular}{|c|c|c|c|}
\hline \multirow{2}{*}{ Компоненты пищи } & \multicolumn{3}{|c|}{$\begin{array}{l}\text { Корюшка, Большой Вудъявр } \\
\text { (min-max длина рыб FL, мм) }\end{array}$} \\
\hline & $90-150$ & $90-120$ & $121-150$ \\
\hline- & $\mathrm{P}, \% / \mathrm{F}, \%$ & $\mathrm{P}, \% / \mathrm{F}, \%$ & $\mathrm{P}, \% / \mathrm{F}, \%$ \\
\hline Зоопланктон & $93.4 / 96.0$ & $90.0 / 100$ & $97.2 / 100$ \\
\hline ветвистоусые рачки & 88.8 / 96.0 & $82.2 / 92.9$ & $94.5 / 100$ \\
\hline веслоногие рачки & $4.6 / 48.0$ & $7.8 / 42.9$ & $2.7 / 54.5$ \\
\hline Бентос: & $3.6 / 40.0$ & $4.0 / 38.5$ & $2.8 / 45.5$ \\
\hline двукрылые (лич., кук.) & $3.6 / 40.0$ & $4.0 / 35.7$ & $2.8 / 45.5$ \\
\hline Аморфная масса & $3.0 / 4.0$ & $6.0 / 7.1$ & - \\
\hline $\begin{array}{l}\text { Средний размер кормовых } \\
\text { организмов, мм }\end{array}$ & $\frac{3.5 \pm 0.4}{0.6-7.4}$ & $\frac{3.3}{0.6-6.9}$ & $\frac{3.6}{1.5-7.4}$ \\
\hline $\begin{array}{l}\text { Средняя масса пищевого } \\
\text { комка, мг }\end{array}$ & $\frac{71 \pm 6.5}{20-160}$ & $20 \frac{63}{-160}$ & $42 \frac{78}{-111}$ \\
\hline Средний Ін, \% & $\frac{54 \pm 4.4}{25-113}$ & $26 \frac{59}{-113}$ & $25-63$ \\
\hline Количество экз. & 25 & 14 & 11 \\
\hline
\end{tabular}

Примечание. Таксономия объектов питания корюшки в оз. Б. Вудъявр: зоопланктон: ветвистоусые рачки Bosmina sp., Dafnia sp, веслоногие рачки - Acantocyclops sp.; бентос: хирономиды - Psectrocladius sp.

\section{Обсуждение}

Исследование спектра питания гольцов и корюшки из оз. Б. и М. Вудъявр выявило, что он включает относительно неширокий набор объектов питания. Это объясняется тем, что зоопланктонное и бентосное сообщества этих озер характеризуется относительно небогатым таксономическим разнообразием на фоне высоких значений численности и биомассы (Кашулин и др., 2008, 2013). Несмотря на то, что оз. М. Вудъявр не подвергается прямому антропогенному воздействию, 
в настоящее время его трофический статус оценивается как эвтрофный, количественные показатели макрозообентоса сопоставимы с таковыми для оз. Б. Вудъявр (Денисов и др., 2018). Количественные показатели зоопланктона в Б. Вудъявре соответствуют мезотрофному трофическому статусу, в М. Вудъявре - олиготрофному. Для гольца в оз. Б. Вудъявр до 300 мм характерен смешанный тип питания (в пищевом комке одинакового по частоте встречаемости и по доле по массе встречается ракообразный зоопланктон и хирономиды) с элементами хищничества. Особи после 300 мм полностью переходят на бентосный тип питания хирономидами с элементами хищничесва девятииглой колюшкой. Для мелкого гольца из оз. М. Вудъявр также характерен смешанный тип питания (ракообразный зоопланктон и хирономиды) с элементами хищничества девятииглой колюшкой практически на всем протяжении жизни. При этом гольцы оз. М. Вудъявр начинают питаться рыбой при меньшей длине, нежели в оз. Б. Вудъявр (табл. 2). Таким образом, особенности питания гольцов из озер Б. и М. Вудъявр схожи, количественные относительные показатели содержимого желудка значимо не различаются. Из полученных данных следует, что разница в линейно-весовых характеристиках гольцов этих озер не определяется разницей в питании. Данная гипотеза требует уточнения в виде изучения сезонного питания гольцов озер Б. и М. Вудъявр и циклов созревания, поскольку блокировка созревания гонад сублетальной токсичностью среды в оз. Б. Вудьявр может результировать в увеличение темпов роста. Также различия размерно-весовых характеристик гольца могут указывать на наличие в системе р. Большая Белая сложной единой полиморфной популяции гольца с горизонтальной или вертикальной формой трансформации в разные внутривидовые размерные группировки, или на наличие двух отдельных популяций гольца озер Б. и М. Вудъявр с разными жизненными циклами. Это требует детального изучения темпов роста гольцов этих озер (Alekseyev et al., 2009) и наличия миграции рыб из одного озера в другое.

Особенности питания корюшки в оз. Б. Вудъявр близки к таковым гольца этого озера: имеет смешанный тип питания (ракообразный зоопланктон и хирономиды) с преобладанием зоопланктонных организмов. При дальнейшем росте численности корюшки в оз. М. Вудъявр возможна конкуренция за зоопланктон между корюшкой и гольцом. При этом присутствие большего количества молоди корюшки может создать условия полного перехода гольца на хищничество, и взаимодействие этих видов будет описываться моделью «хищник-жертва» при наличии условий для успешного воспроизводства гольца.

Работа выполнена в рамках темы НИР № 0226-2019-0045 (полевые работы на озерах Б. и М. Вудъявр) и частично поддержана из средств гранта РФФИ 18-05-60125 Арктика (интерпретация результатов по ихтиологическим показателям гольца из оз. М. Вудъявр) и РНФ № 19-77-10007 (интерпретация результатов по ихтиологическим показателям гольца и корюшки оз. Б. Вудъявр).

\section{Литература}

1. Денисов Д.Б., Валькова С.А. Кашулин Н.А. Водорослевые сообщества и макрозообентос водных экосистем Хибинского горного массива (Кольский полуостров) // Вестник Кольского научного центра PAH. 2018. № 1. C. 23-35.

2. Кашулин Н.А., Денисов Д.Б., Сандимиров С.С., Даувальтер В.А., Кашулина Т.Г., Малиновский Д.Н., Вандыш О.И., Ильяшук Б.П., Кудрявцева Л.П. Антропогенные изменения водных систем Хибинского горного массива (Мурманская область). Апатиты. Изд-во: КНЦ РАН. 2008. Т. 1. 250 с.; Т. 2. 282 с.

3. Кашулин Н.А., Сандимиров С.С., Даувальтер В.А., Кудрявцева Л.П., Терентьев П.М., Денисов Д.Б., Вандыш О.И., Королева И.М., Валькова С.А., Кашулина Т.Г. Аннотированный экологический каталог озер Мурманской области: центральный и юго-западный районы Мурманской области (бассейны Баренцева и Белого морей и Ботнического залива Балтийского моря). В 2 ч. Апатиты. Изд-во: КНЦ РАН, 2013. Ч. 2. $253 \mathrm{c}$.

4. Материалы к изучению вод Кольского пол-ва. Собрание1. Москва. Изд-во: АН СССР. 1940. 256 с.

5. Методическое пособие по изучению питания и пищевых отношений рыб в естественных условиях. М. Изд-во: Наука.1974. 254 с.

6. Михайлов В.Н., Добровольский А.Д., Добролюбов С.А. Гидрология: учебник для вузов. 2-е изд. испр. М. Изд-во: Высш. Шк. 2007. 463 с. 
7. Решетников Ю.С., Богданов В.Д. Особенности воспроизводства сиговых рыб. Вопр. Ихтиологии. 2011. T. 51. № 4. C. 502-525.

8. Руководство по изучению питания рыб в естественных условиях. М. Изд-во: АН СССР. 1961. 262 с.

9. Терентьев П.М. Сравнительная оценка антропогенной нагрузки на организмы гольца Salvelnus alpines водоемов Мурманской области в условиях разнотипного загрязнения // Тезисы докладов Международной конференции с элементами научной школы для молодёжи «Проблемы экологии». Иркутск, 20-25 сентября 2010 г. Иркутск. 2010. С. 115.

10. Терентьев П.М., Кашулин Н.А., Зубова Е.М. Роль европейской корюшки Osmerus eperlanus (Linnaeus) в структуре ихтиофауны бассейна оз. Имандра (Мурманская область) // Труды Зоологического института РАН. 2017. T. 321. №. 2. C. 228-243.

11. Alekseyev S.S., Mina M.V., Smirins E.M., Sokolov A.A. Late ontogeny growth acceleration and size form transformations in Transbaikalian Arctic charr, Salvelinus alpinus complex: evidence from fin ray cross section growth layers // Environ. Biol. Fish. 2009. V. 86. P. 487-505. 